\title{
Article \\ Comprehensive Stability Study of Vitamin D3 in Aqueous Solutions and Liquid Commercial Products
}

\author{
Žane Temova Rakuša, Mitja Pišlar, Albin Kristl and Robert Roškar *(D) \\ Faculty of Pharmacy, University of Ljubljana, Aškerčeva Cesta 7, 1000 Ljubljana, Slovenia; \\ zane.temova.rakusa@ffa.uni-lj.si (Ž.T.R.); mitja.pislar@gmail.com (M.P.); albin.kristl@ffa.uni-lj.si (A.K.) \\ * Correspondence: robert.roskar@ffa.uni-lj.si; Tel.: +386-1-4769-500
}

check for updates

Citation: Temova Rakuša, Ž.; Pišlar, M.; Kristl, A.; Roškar, R. Comprehensive Stability Study of Vitamin D3 in Aqueous Solutions and Liquid Commercial Products. Pharmaceutics 2021, 13, 617. https://doi.org/ 10.3390/pharmaceutics13050617

Academic Editor: Beverley D. Glass

Received: 8 April 2021

Accepted: 23 April 2021

Published: 25 April 2021

Publisher's Note: MDPI stays neutral with regard to jurisdictional claims in published maps and institutional affiliations.

Copyright: (c) 2021 by the authors. Licensee MDPI, Basel, Switzerland. This article is an open access article distributed under the terms and conditions of the Creative Commons Attribution (CC BY) license (https:// creativecommons.org/licenses/by/ $4.0 /)$.

\begin{abstract}
Vitamin D3 has numerous beneficial effects, such as musculoskeletal, immunomodulatory, and neuroprotective. However, its instability is the main obstacle to formulating quality products. Despite increased attention and growing use, data on vitamin D3 stability is scarce because data from individual studies is inconclusive and mostly qualitative. Therefore, we have systematically investigated the influence of various factors (temperature, light, oxygen, $\mathrm{pH}$, concentration, and metal ions) on its stability in aqueous media using a stability-indicating HPLC-UV method. First-order kinetics fitted its degradation under all tested conditions except light and oxygen. In both cases, the established models in chemical kinetics were inappropriate and upgraded with the Weibull model. Metal ions and acidic conditions had the main destabilizing effect on vitamin D3 in aqueous media, but these solutions were successfully stabilized after the addition of ethylenediaminetetraacetic acid (EDTA), ascorbic acid, and citric acid, individually and in combination. EDTA showed the most significant stabilizing effect. Synergism among antioxidants was not observed. Our findings on vitamin D3 instability in aqueous media also correlated with its instability in commercial products. Vitamin D3 aqueous products require proper stabilization, thereby signifying the importance and contribution of the obtained results to the formulation of stable and quality products.
\end{abstract}

Keywords: antioxidants; cholecalciferol; degradation kinetics; food supplements; HPLC-UV; medicines; stability; stabilization

\section{Introduction}

The major role of vitamin $\mathrm{D}$ is to maintain calcium and bone homeostasis through its effects on the intestine, skeleton, parathyroid glands, and kidneys. Vitamin D promotes dietary calcium and phosphate absorption in the small intestine, mobilizes calcium from bones, and modulates the parathyroid function [1-3]. In recent years, many studies have paid attention to non-classic vitamin D actions, such as suppression of cell growth, regulation of apoptosis, modulation of immune responses, control of the nervous system, insulin secretion, and muscle function [4-14]. The number of such publications has substantially increased because of COVID-19, given the positive role of vitamin D on the immune response [15-24]. Vitamin D deficiency is a highly prevalent condition affecting approximately one billion people worldwide [25,26]. Pharmacologically, vitamin D is typically used in dosages of 400 to 1000 international units per day to prevent rickets in infants and young children, supplement the diet of pregnant and lactating women, and prevent and treat of primary and secondary osteoporosis [27]. Vitamin D3 can be found in various dosage forms: oil- or water-soluble capsules, tablets, concentrates (oil, powder, or water-dispersible form), injections, sprays, and oral solutions. Vitamin D3 medicines and food supplements, especially for paediatric use, are typically solutions with various excipients, including compounds that have a potential stabilizing effect, which was evaluated in this study.

However, vitamin D3 is problematic in terms of stability, especially in aqueous media, which is evident from the shorter shelf lives of medicines and food supplements (one or 
two years) [27]. A study dealing with vitamin D3 stability in liquid prescription medicines and supplements after being opened showed that its content decreased considerably in formulations that had not been properly stabilized [28]. Drug stability is one of the key segments in quality assurance, and knowledge about the stability of the active ingredients is crucial for formulating suitable finished products [29]. Despite its frequent use, only a few studies have researched elementary vitamin D3 stability. It is known that various factors, such as exposure to light, humidity, oxygen, temperature, and $\mathrm{pH}$ may affect the stability of vitamin D3; however, the literature [30-44] provides qualitative and often contradictory data. As none of the published studies provides detailed data on its stability (e.g., $\mathrm{pH}$ profile, Arrhenius relationship), the focus of this study was to systematically and statistically evaluate vitamin D3 stability in aqueous solutions. Stability data was kinetically evaluated, which is an additional contribution of this study since vitamin D3 degradation kinetics have not yet been described. The effects of various factors (medium, light, temperature, oxygen, $\mathrm{pH}$, and metal ions) on its stability were thus examined. The stability evaluation also included liquid finished products under three storage conditions. Additionally, potential approaches for improving vitamin D3 stability in aqueous solutions are proposed.

\section{Materials and Methods}

\subsection{Materials}

Vitamin D3 (98\%), ascorbic acid (A), sodium hydroxide $(\mathrm{NaOH})$, propylene glycol (PG), isopropanol (Isoprop) as well as acetonitrile (ACN), and methanol (MeOH) (both HPLC-grade) were purchased from Sigma-Aldrich (Steinheim, Germany). Hydrochloric acid $(\mathrm{HCl}, 37 \%)$, phosphoric acid $\left(\mathrm{H}_{3} \mathrm{PO}_{4}, 85 \%\right)$, ethylenediaminetetraacetic acid disodium salt dihydrate (EDTA), citric acid (C), copper(II) chloride dehydrate $\left(\mathrm{Cu}^{2+}\right)$, copper(I) iodide $\left(\mathrm{Cu}^{+}\right)$, iron(II) sulfate heptahydrate $\left(\mathrm{Fe}^{2+}\right)$, potassium dihydrogen phosphate $\left(\mathrm{KH}_{2} \mathrm{PO}_{4}\right)$, and disodium hydrogen phosphate $\left(\mathrm{Na}_{2} \mathrm{HPO}_{4}\right)$ were purchased from Merck (Darmstadt, Germany). A $30 \% \mathrm{H}_{2} \mathrm{O}_{2}$ solution was purchased from Honeywell Fluka ${ }^{\mathrm{TM}}$ (Seelze, Germany). Ethanol (EtOH, 96.6\%) was purchased from Gram mol (Zagreb, Croatia). Oxygen $\left(\mathrm{O}_{2}, 99.9 \%\right)$ was obtained from Messer, Slovenia. High purity Milli-Q water (MQ) was obtained through a Milli-Q A10 Advantage water purification system (Millipore Corporation, Bedford, MA, USA). Distilled water (DW) was obtained through an Elix ${ }^{\circledR}$ Water Purification System (Merck, Darmstadt, Germany). Tap water (TW) was obtained from the laboratory at the Faculty of Pharmacy, University of Ljubljana (Ljubljana, Slovenia).

\subsection{Instrumentation and Chromatographic Conditions}

Vitamin D3 content was analysed according to a published stability-indicating method using a high-performance liquid chromatograph (HPLC) Agilent 1100/1200 Series instrument (Agilent Technologies, Santa Clara, CA, USA) equipped with a UV detector and ChemStation data acquisition system. In brief, a reversed-phase column Gemini C18 $100 \times 3.0 \mathrm{~mm}, 3 \mu \mathrm{m}$ particle size column (Phenomenex, Torrance, CA, USA) at $40{ }^{\circ} \mathrm{C}$ was used with a mobile phase of acetonitrile water $(99: 1, v / v)$ at a flow rate of $1 \mathrm{~mL} / \mathrm{min}$. The detection was carried out at $265 \mathrm{~nm}$ [42]. The injection volume for samples within the vitamin D3 stability study in aqueous solutions was $20 \mu \mathrm{L}$, except for the samples with different vitamin D3 concentrations (between 2 and $50 \mu \mathrm{L}$ ). The injection volume for analysis of the tested finished products was adjusted to vitamin D3 content (between 2 and $20 \mu \mathrm{L})$.

\subsection{Sample Preparation}

\subsubsection{Samples for Vitamin D3 Stability Study in Aqueous Solutions}

A fresh stock vitamin D3 solution (1000 mg/L) was prepared daily by precisely dissolving $10 \mathrm{mg}$ of vitamin D3 standard in a $10.0 \mathrm{~mL}$ flask with $\mathrm{MeOH}$. Further dilutions of this solution were prepared in various solvents to a concentration of $20 \mathrm{mg} / \mathrm{L}$ to evaluate the effect of various factors on vitamin D3 stability (Table 1). An additional stock solution 
with $5000 \mathrm{mg} / \mathrm{L}$ of vitamin $\mathrm{D} 3$ in $\mathrm{MeOH}$ was prepared and properly diluted with MQ and $\mathrm{MeOH}$ to evaluate the concentration effect in solutions containing $10 \% \mathrm{MeOH}$ in $\mathrm{MQ}$. To evaluate the effect of temperature, the solutions were stored at 25 and $40{ }^{\circ} \mathrm{C}$ in a VC 4034 climatic chamber (Vötsch, Reiskirchen-Lindenstruth, Germany) and ICH 260L climatic chamber (Memmert, Schwabach, Germany), respectively, and at $4{ }^{\circ} \mathrm{C}$ in a refrigerator (Gorenje, Velenje, Slovenija). Buffer solutions with different $\mathrm{pH}$ values were prepared by mixing appropriate volumes of $50.0 \mathrm{mM} \mathrm{KH}_{2} \mathrm{PO}_{4}$ and $\mathrm{Na}_{2} \mathrm{HPO}_{4}$ solutions in $\mathrm{DW}$ to the same volume $(50 \mathrm{~mL})$. Their $\mathrm{pH}$ values were measured using a calibrated $\mathrm{pH}$ meter and adjusted to the desired value with dilute $\mathrm{H}_{3} \mathrm{PO}_{4}$ or $\mathrm{NaOH}$. Aqueous solutions were exposed to daylight in clear vials for up to $6 \mathrm{~h}$ to evaluate the effect of light. The effect of oxygen was evaluated by comparing aqueous solutions blown with oxygen every few hours with the control group (same concentration and storage conditions subjected to air). Additionally, different volumes of the aqueous solutions were transferred into vials to evaluate the impact of the air space. The effects of metal ions $\left(\mathrm{Fe}^{2+}, \mathrm{Cu}^{+}\right.$, and $\left.\mathrm{Cu}^{2+}\right)$ were evaluated by dissolving $\mathrm{FeSO}_{4} \cdot 7 \mathrm{H}_{2} \mathrm{O}, \mathrm{CuI}$, or $\mathrm{CuCl}_{2} \cdot 2 \mathrm{H}_{2} \mathrm{O}$ in $\mathrm{MQ}$, in which the stock solution was diluted. Vitamin D3 stability was also evaluated in the presence of a combination of $\mathrm{Cu}^{2+}$ ions $(2 \mathrm{mM})$ and different concentrations of ascorbic acid. The effects of various EDTA, ascorbic acid, and citric acid concentrations were also evaluated. Antioxidant stabilization efficiency was further evaluated in their combinations (more data is provided in Appendix A Table A1).

Table 1. Selected parameters along with tested conditions within the vitamin D3 stability study in aqueous solutions (vitamin D3 concentration $=20 \mathrm{mg} / \mathrm{L}$ unless otherwise stated).

\begin{tabular}{|c|c|c|}
\hline Parameter & Media & Varied Condition \\
\hline media & different & $\begin{array}{c}\text { aqueous (DW, TW, } \mathrm{MQ}) \text { and organic }(\mathrm{EtOH}, \mathrm{EtOH}+\mathrm{MeOH} \text {, } \\
\text { Isoprop., } \mathrm{MeOH}, \mathrm{PG})\end{array}$ \\
\hline temperature & TW/DW/MQ & $4{ }^{\circ} \mathrm{C}, 25{ }^{\circ} \mathrm{C}, 40^{\circ} \mathrm{C}$ \\
\hline $\mathrm{pH}$ & DW & $\mathrm{pH}: 1,2,3,4,5,6,7,8$ \\
\hline concentration & MQ -MeOH $(90: 10, v / v)$ & $10,25,100$ and $500 \mathrm{mg} / \mathrm{L}$ \\
\hline light & DW & clear vials exposed to daylight, amber vials kept in the dark \\
\hline oxygen & DW & with or without $\mathrm{O}_{2}$ \\
\hline air space & $\mathrm{MeOH}-\mathrm{DW}(75: 25, v / v)$ & solution volume in $2-\mathrm{mL}$ vials $(0.5,1.0,1.5$ and $2.0 \mathrm{~mL})$ \\
\hline $\mathrm{Fe}^{2+}, \mathrm{Cu}^{+}$or $\mathrm{Cu}^{2+}$ ions & $\mathrm{MQ}$ & $0.01,0.05,0.1 \mathrm{mM}$ \\
\hline $\mathrm{Cu}^{2+}+\mathrm{A}$ & $\mathrm{DW}$ & $\mathrm{CuCl}_{2}(2 \mathrm{mM})+\mathrm{A}(0,100,200,500,1000,2000 \mathrm{mg} / \mathrm{L})$ \\
\hline A & DW & $\mathrm{A}(100,200,500,1000,2000 \mathrm{mg} / \mathrm{L})$ \\
\hline EDTA & DW & EDTA $(50,100,200,500,1000 \mathrm{mg} / \mathrm{L})$ \\
\hline C & DW & $\mathrm{C}(5,10,50,100,500 \mathrm{mg} / \mathrm{L})$ \\
\hline A, EDTA and/or C* & DW & $\begin{array}{c}\text { A }(500,2000,5000 \mathrm{mg} / \mathrm{L}) ; \operatorname{EDTA}(200,500,1000 \mathrm{mg} / \mathrm{L}) ; \mathrm{C}(5, \\
50,500 \mathrm{mg} / \mathrm{L})\end{array}$ \\
\hline
\end{tabular}

A—ascorbic acid; C—citric acid; DW—distilled water; EtOH—ethanol; $\mathrm{EtOH}+\mathrm{MeOH}-50: 50$, v/v; Isoprop-isopropanol; $\mathrm{MeOH}-$ methanol; MQ-Milli-Q water; PG—propylene glycol; TW—-tap water; * Combinations of two or three antioxidants in different concentrations (see Appendix A Table A1).

Each sample was prepared in at least three replicates. All samples were stored in amber vials, except for those used for studying the influence of light, and at $25{ }^{\circ} \mathrm{C}$, apart from the samples used to examine the influence of oxygen $\left(15^{\circ} \mathrm{C}\right)$ and temperature $\left(4,25\right.$, and $\left.40^{\circ} \mathrm{C}\right)$. The vitamin D3 concentration was $20 \mathrm{mg} / \mathrm{L}$ in all samples, except when evaluating the effect of its concentration.

\subsubsection{Vitamin D3 Stability Study in Liquid Commercial Products}

Three different medicines and six food supplements (FSs), commercially available on the European market, all in the form of oral drops were analysed. The analysed products included: AD3 (Krka, Novo Mesto, Slovenia), Baby-D (Jamieson, Toronto, ON, Canada), D-drops (Calivita International, California City, CA, USA), D-vitamin Olja (DunMedic, Stockholm, Sweden), Plivit D3 (Pliva, Zagreb, Croatia), Liquid vitamin D3 (Nutrilab, Irvine, 
CA, USA), Vigantol (Merck, Darmstadt, Germany), Vitamin AD3 drops (Iva-Farm, Valjevo, Serbia) and Vitamin D droplets (Jamieson, Toronto, ON, Canada). More detailed information on the analysed products is summarized in Table 2. After opening, every sample (prepared in triplicate) was directly injected into a high-performance, liquid-chromatography system with ultraviolet detection (HPLC-UV) to obtain the initial vitamin D3 content. The products were further stored in climatic chambers at 25 and $40{ }^{\circ} \mathrm{C}$, and in a refrigerator at $4{ }^{\circ} \mathrm{C}$. The samples were analysed regularly within six months to assess vitamin D3 stability. The results of the vitamin D3 stability study in the finished products are presented as a percentage of its content in relation to the initial content along with the standard error of the mean.

Table 2. Data on the tested products.

\begin{tabular}{|c|c|c|c|c|c|}
\hline \multirow{2}{*}{ Product } & \multirow{2}{*}{ Type } & \multirow{2}{*}{$\begin{array}{l}\text { Vitamin D3 } \\
\text { Content }\end{array}$} & \multicolumn{3}{|c|}{ Ingredients } \\
\hline & & & Carrier & Potential Stabilizers & Other Excipients \\
\hline 1 & M & $20,000 \mathrm{IU} / \mathrm{mL}$ & MCT & & \\
\hline 2 & M & $4000 \mathrm{IU} / \mathrm{mL}$ & PW & $\begin{array}{l}\text { BHT, anhydrous citric } \\
\text { acid, propylene glycol }\end{array}$ & $\begin{array}{l}\text { methyl parahydroxybenzoate, } \\
\text { MGHS, macrogol 400, anhydrous } \\
\text { sodium hydrogen phosphate }\end{array}$ \\
\hline 3 & M & $2000 \mathrm{IU} / \mathrm{mL}$ & PW & $\begin{array}{l}\text { glycerol, propylene } \\
\text { glycol }\end{array}$ & $\begin{array}{c}\text { MGHS, sodium benzoate, sucrose, } \\
\text { sodium saccharinate, orange } \\
\text { aroma (ethanol) }\end{array}$ \\
\hline 4 & FS & $1000 \mathrm{IU} /$ drop & MCT & & \\
\hline 5 & FS & $12,000 \mathrm{IU} / \mathrm{mL}$ & deionized water & $\begin{array}{l}\text { citric acid, vegetable } \\
\text { glycerine }\end{array}$ & $\begin{array}{c}\text { natural orange aroma, lemon } \\
\text { essential oil }\end{array}$ \\
\hline 6 & FS & $400 \mathrm{IU} /$ drop & corn oil & & \\
\hline 7 & FS & $4000 \mathrm{IU} / \mathrm{mL}$ & PW & & sodium benzoate \\
\hline 8 & FS & $80 \mathrm{IU} /$ drop & vegetable oil & & \\
\hline 9 & FS & $320 \mathrm{IU} / \mathrm{mL}$ & PW & vegetable glycerine & $\begin{array}{l}\text { stevia, natural cherries aroma, } \\
\text { potassium sorbate, and sodium } \\
\text { benzoate }\end{array}$ \\
\hline
\end{tabular}

BHT—butylated hydroxytoluene; FS—food supplement; M—medicine; MCT—-medium-chain triglycerides; MGHS—macrogolglycerol hydroxystearate; PW—-purified water. * as stated on the packaging of the product.

\subsection{Kinetics Calculations and Data Analysis}

The results are expressed as the mean of at least three different measurements along with the standard error of the mean. Zero-, first- and second-order kinetics as well as the Weibull model were fitted to vitamin D3 degradation by using a nonlinear least-square regression function from base "stats" package in R statistical software [45]. Fitted models were evaluated by R-squared and the Akaike information criterion (AIC). The rate constants for different stability conditions were determined based on the most adequate model. If comparable to Weibull kinetic model, the first-order model was primarily used due to its simplicity. The estimated rate constants were analysed with one-way ANOVA and further compared by $95 \%$ confidence intervals and post hoc tests (Tukey and Bonferroni-Holm post hoc test). MS Excel (Excel version 2013) and R (R version 4.0.2) software were used for data analysis.

\section{Results}

\subsection{Degradation Kinetics}

The modelling process included the experimental data obtained from the vitamin D3 stability study in aqueous solutions. The fitting of several kinetic models to vitamin D3 degradation is shown under the influence of light, oxygen, and other tested conditions (representative data provided for distilled water, $\mathrm{Cu}^{2+}$ ions, and $\mathrm{pH}=1$ ) (Table 3). The model with the highest coefficient of determination $\left(R^{2}\right)$ and the lowest Akaike information criterion (AIC) was selected. 
Table 3. Kinetic models for vitamin D3 degradation under different conditions.

\begin{tabular}{|c|c|c|c|c|c|c|c|c|c|c|}
\hline \multirow[b]{3}{*}{ Model } & \multirow{2}{*}{\multicolumn{2}{|c|}{ Light }} & \multirow{2}{*}{\multicolumn{2}{|c|}{ Oxygen }} & \multicolumn{6}{|c|}{ Other Conditions * } \\
\hline & & & & & \multicolumn{2}{|c|}{ DW } & \multicolumn{2}{|c|}{$\mathrm{Cu}^{2+}$} & \multicolumn{2}{|c|}{$\mathrm{pH}=\mathbf{1}$} \\
\hline & $R^{2}$ & AIC & $R^{2}$ & AIC & $R^{2}$ & AIC & $R^{2}$ & AIC & $R^{2}$ & AIC \\
\hline $\begin{array}{l}\text { 0. order: } \\
\qquad y=100-\mathrm{k} \times \mathrm{t}\end{array}$ & 0.906 & 344.8 & 0.947 & 475.6 & 0.892 & 164.8 & 0.758 & 109.8 & 0.826 & 102.6 \\
\hline $\begin{array}{l}\text { 1. } \quad \text { order: } \\
y=100 * \exp (-\mathrm{k} \times \mathrm{t})\end{array}$ & 0.796 & 379.4 & 0.918 & 505.0 & 0.982 & 127.3 & 1.000 & 14.30 & 0.995 & 61.45 \\
\hline $\begin{array}{l}\text { 2. } \\
\text { order: } \\
\qquad y=100 /(1+k \times t)\end{array}$ & 0.698 & 397.1 & 0.843 & 549.0 & 0.903 & 162.5 & 0.986 & 75.55 & 0.989 & 69.02 \\
\hline Weibull:y $=100 * \exp \left(-(\mathrm{t} / \lambda)^{\wedge} k\right)$ & 0.994 & 225.7 & 0.973 & 431.8 & 0.997 & 89.28 & 1.000 & 1.616 & 0.998 & 52.43 \\
\hline
\end{tabular}

$R^{2}$ —coefficient of determination; AIC—the Akaike information criterion; $\mathrm{k}$-slope (rate constant); $\mathrm{t}$-time [h]; $\lambda$-scale parameter; $k$-shape parameter; ${ }^{*}$ representative data provided for distilled water, $\mathrm{Cu}^{2+}$ ions, and $\mathrm{pH}=1$.

The degradation of vitamin D3 in almost all cases followed the first-order kinetic model (Table 3-other conditions). The first-order kinetic model was less suitable for its degradation under exposure to light and oxygen. In these two cases, vitamin D3 degradation was most adequately described by the Weibull model. For vitamin D3 degradation in other tested conditions, Weibull kinetic model was found comparable to the first-order model, but the latter was used due to its simplicity.

\subsection{Vitamin D3 Stability Study in Aqueous Solutions}

The influence of various factors including temperature, $\mathrm{pH}$, concentration, light, oxygen, and metal ions on the stability of vitamin D3 in aqueous solutions was systematically investigated and quantitatively and statistically evaluated.

\subsubsection{Effect of the Media}

Vitamin D3 stability was evaluated in DW and selected organic solvents including $\mathrm{EtOH}, \mathrm{MeOH}$, their mixture (50:50, v/v), Isoprop, and PG. Contrary to aqueous solutions, vitamin D3 was very stable in the tested non-aqueous solutions within the tested period of five days (Figure 1). Differences among the non-aqueous solutions were not significant (ANOVA, $p>0.05$ ). Vitamin D3 was found very unstable in DW as its concentration dropped below $10 \%$ of the initial content after the first day of storage at $25^{\circ} \mathrm{C}$ (Figure 1). Its stability was also significantly different in the three evaluated aqueous media: MQ, DW, and TW. Vitamin D3 was found to be the most stable in MQ and the least stable in DW (Table 4).

Table 4. First-order rate constants for vitamin D3 at various temperatures in Milli-Q (MQ), distilled (DW), and tap water (TW), along with the Arrhenius equation.

\begin{tabular}{cccc}
\hline & DW & TW & MQ \\
\hline $\mathrm{k}_{1}\left(4^{\circ} \mathrm{C}\right)\left(\mathrm{h}^{-1]}(\mathrm{CI})\right.$ & $0.027(0.023-0.031)$ & $0.012(0.009-0.014)$ & $0.001(0.000-0.002)$ \\
$\mathrm{k}_{1}\left(25^{\circ} \mathrm{C}\right)\left(\mathrm{h}^{-1}\right)(\mathrm{CI})$ & $0.143(0.124-0.162)$ & $0.099(0.096-0.102)$ & $0.024(0.021-0.026)$ \\
$\mathrm{k}_{1}\left(40^{\circ} \mathrm{C}\right)\left(\mathrm{h}^{-1}\right)(\mathrm{CI})$ & $0.400(0.385-0.416)$ & $0.339(0.270-0.407)$ & $0.085(0.077-0.092)$ \\
Arrhenius equation & $\mathrm{y}=-6465 \mathrm{x}+19.74$ & $\mathrm{y}=-8142 \mathrm{x}+24.96$ & $\mathrm{y}=-10,725 \mathrm{x}+31.97$ \\
$R^{2}$ & 1.000 & 0.999 & 0.988 \\
Ea $(\mathrm{kJ} / \mathrm{mol})$ & 53.8 & 67.7 & 89.2 \\
\hline CI-95\% confidence interval; Ea-activation energy. & &
\end{tabular}




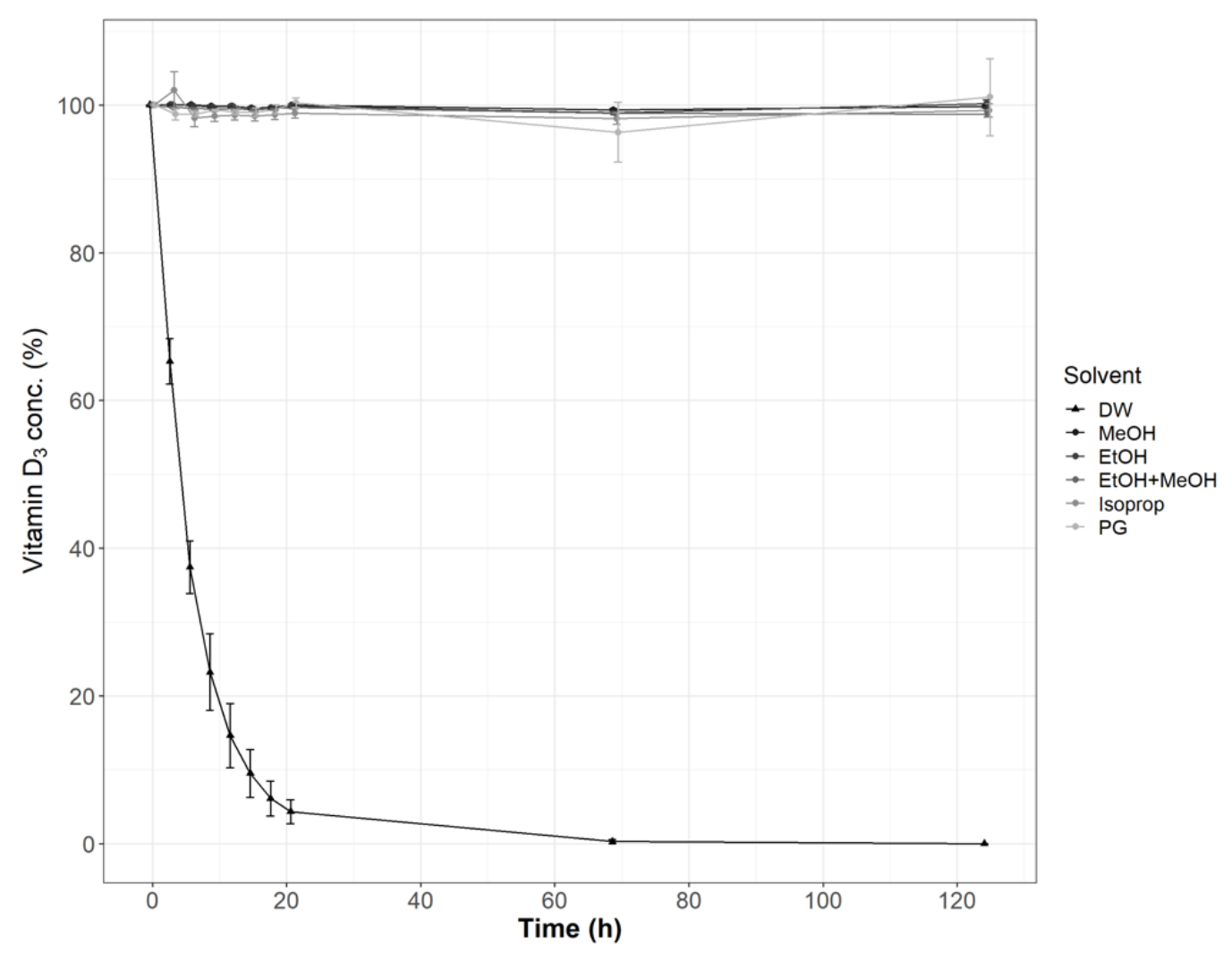

Figure 1. Effect of the media on vitamin D3 stability at $25{ }^{\circ} \mathrm{C}(n=3)$.

\subsubsection{Temperature Effect}

Vitamin D3 stability was evaluated at three isothermal conditions: 4,25 and $40{ }^{\circ} \mathrm{C}$ in three different aqueous media: MQ, DW, and TW. The results of the impact of temperature on vitamin D3 stability are presented by the first-order rate constants $\left(k_{1}\right)$ in Table 4. Higher temperature led to a statistically significant increase in reaction rate constants. High correlations $\left(R^{2}\right)$ between calculated rate constants and temperature showed that vitamin D3 degradation in all three aqueous media followed the Arrhenius equation, based on which activation energies were calculated.

\subsection{3. $\mathrm{pH}$ Effect}

The impact of $\mathrm{pH}$ in the range between 1 and 8 at $25^{\circ} \mathrm{C}$ on the stability of vitamin D3 was systematically evaluated. First-order rate constants fitted vitamin D3 degradation well and were calculated for each $\mathrm{pH}$ value based on the time points up to the 6th hour (Figure 2). With a steep drop in stability between $\mathrm{pH}$ values 4 and 5, vitamin D3 was found most stable at a $\mathrm{pH}$ above 5. Statistical method ANOVA revealed no significant differences between the first-order rate constants at $\mathrm{pH}$ values between 5 and $8(p>0.05)$. Vitamin D3 was found very unstable under acidic conditions, with an apparent trend of decreasing stability towards lower $\mathrm{pH}$ values, with statistically significant differences in the first-order rate constants at $\mathrm{pH}$ values between 1 and 4 , as showed by ANOVA $(p<0.05)$ and Bonferroni-Holm post hoc test ( $p<$ critical values). 


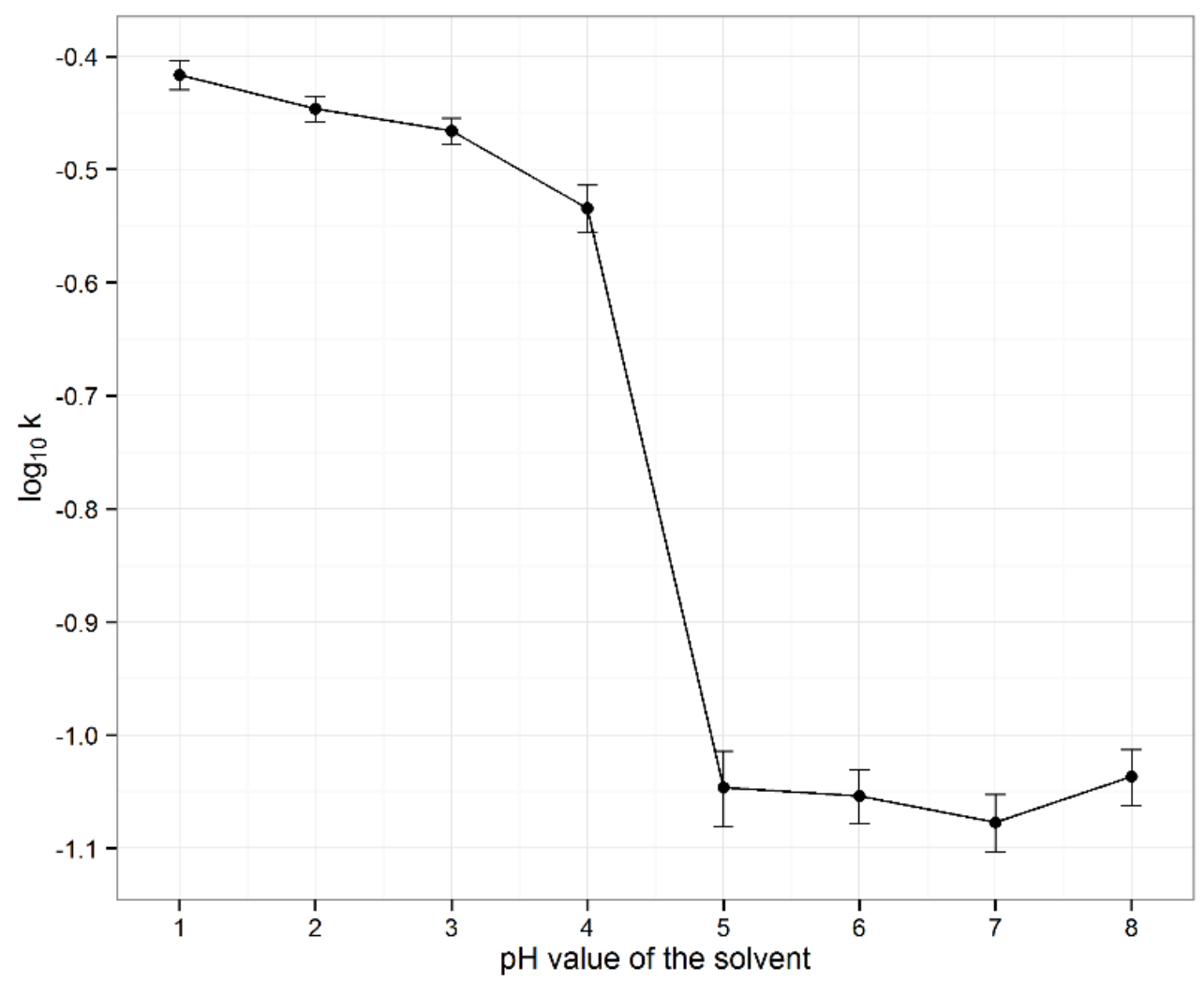

Figure 2. $\mathrm{pH}$ profile of vitamin $\mathrm{D} 3$ in aqueous solutions at $25^{\circ} \mathrm{C}(n=3)$.

\subsubsection{Effect of Vitamin D3 Concentration}

The effect of different vitamin D3 concentrations on its stability in aqueous solutions was further evaluated. Vitamin D3 stability was found concentration-dependent, with significantly higher first-order rate constants in solutions with its lower concentrations (Table 5).

Table 5. First-order rate constants for vitamin D3 at different concentrations in Milli-Q watermethanol $(90: 10, v / v)$ at $25^{\circ} \mathrm{C}(n=3)$.

\begin{tabular}{|c|c|c|c|c|}
\hline $\begin{array}{l}\text { Vitamin D3 } \\
\text { Concentration }\end{array}$ & $10 \mathrm{mg} / \mathrm{L}$ & $25 \mathrm{mg} / \mathrm{L}$ & $100 \mathrm{mg} / \mathrm{L}$ & $500 \mathrm{mg} / \mathrm{L}$ \\
\hline $\begin{array}{c}\mathrm{k}_{1}\left(\mathrm{~h}^{-1}\right) \\
(\mathrm{CI})\end{array}$ & $\begin{array}{c}0.055 \\
(0.050-0.060)\end{array}$ & $\begin{array}{c}0.047 \\
(0.046-0.049)\end{array}$ & $\begin{array}{c}0.035 \\
(0.032-0.037)\end{array}$ & $\begin{array}{c}0.024 \\
(0.024-0.025)\end{array}$ \\
\hline
\end{tabular}

\section{CI-95\% confidence interval.}

\subsubsection{Effect of Light Exposure}

The effect of light on vitamin D3 stability was also evaluated. Its content in DW was higher at all time-points in samples protected from light (Figure 3). Based on the parameters of the fitted Weibull model, the differences in degradation kinetics were statistically significant. Presence of light reduced the scale parameter $(\lambda)$ by $1.04 \mathrm{~h}(p<0.001)$ and increased the shape parameter $(k)$ by 0.36 units $(p<0.001)$. 


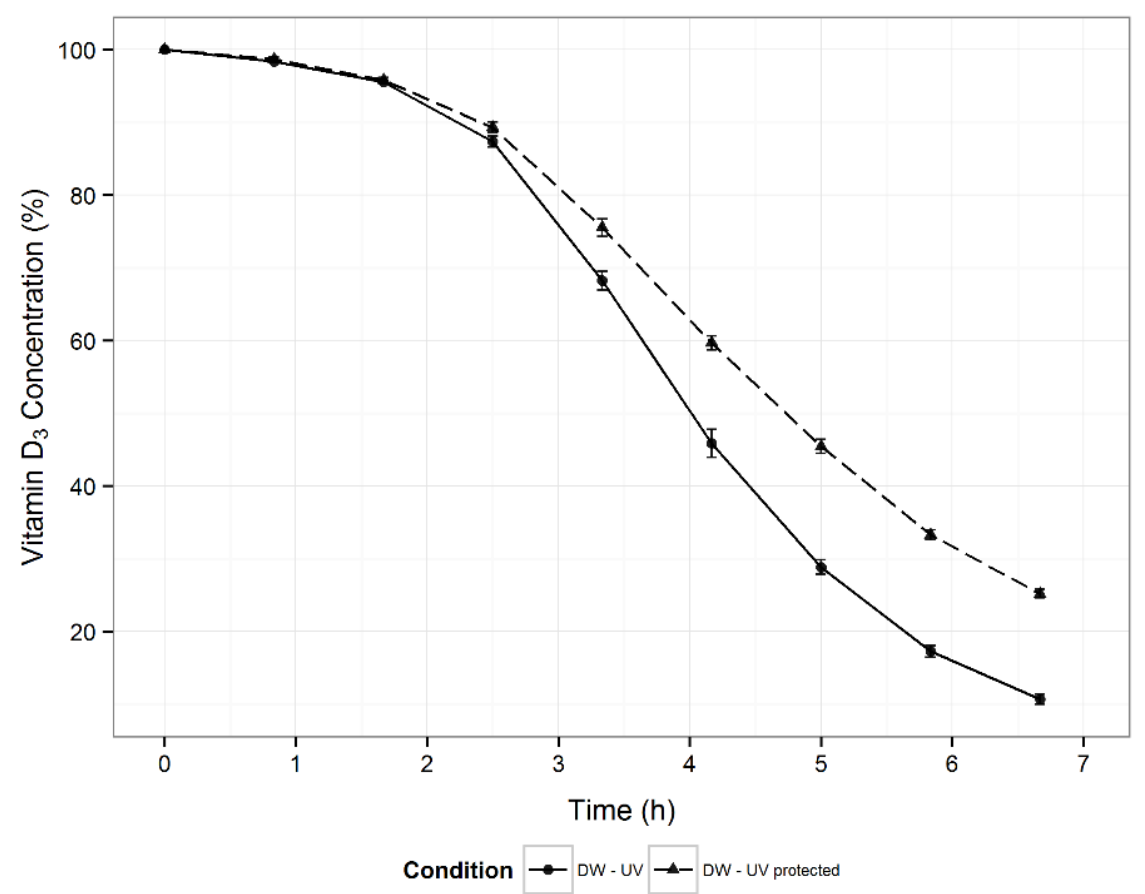

Figure 3. Stability of vitamin D3 in distilled water solutions exposed to light (DW-UV) and protected from light (DW-UV protected) at $25^{\circ} \mathrm{C}(n=5)$.

\subsubsection{Effect of Oxygen}

To clarify whether exposure to oxygen affects the stability of vitamin D3, an experiment was conducted in which its aqueous solution was blown with oxygen. The results (Figure 4) were compared with the control samples using the Weibull model, which most adequately described vitamin D3 degradation under these conditions. The fitted model showed a statistically significant difference in vitamin D3 degradation, as the presence of oxygen reduced the scale parameter $(\lambda)$ by $13.7 \mathrm{~h}(p<0.001)$ and shape parameter $(k)$ by 0.44 units $(p<0.001)$ of the Weibull model.

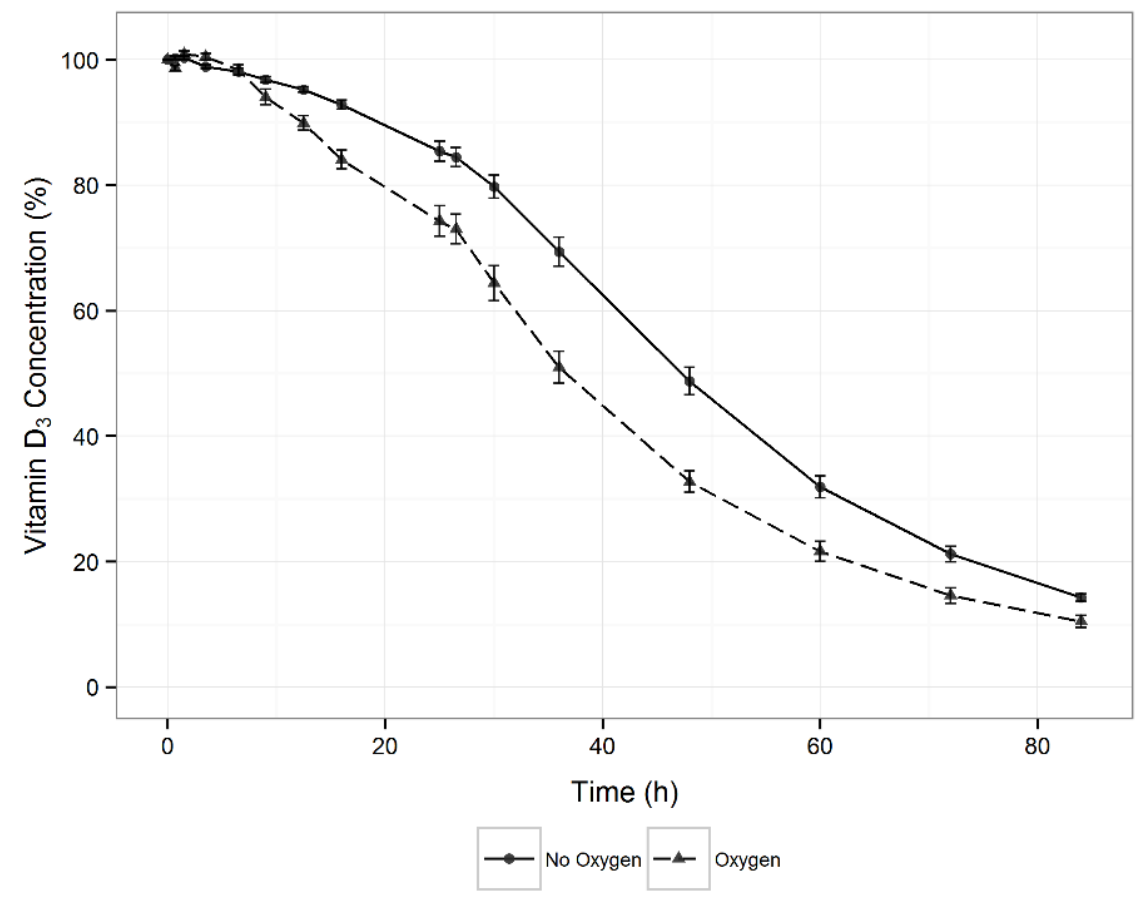

Figure 4. Effect of oxygen on vitamin D3 stability at $15^{\circ} \mathrm{C}(n=5)$. 
An additional experiment was conducted to evaluate whether the air space above the solution (headspace in vials) affects vitamin D3 stability. The samples were prepared in a mixture of $\mathrm{MeOH}$ and DW $(75: 25, v / v)$, as a medium in which vitamin D3 is more stable and permits a more accurate evaluation of its degradation. Comparing the degradation rates of vitamin D3 in $2 \mathrm{~mL}$ vials with different amounts of the same solution (from 0.5 to $2.0 \mathrm{~mL}$, Table 1) it was evident that the air above the solution did not significantly affect its stability (ANOVA, $p>0.05$ ).

\subsubsection{Effect of Metal Ions}

The effects of different concentrations of $\mathrm{Fe}^{2+}, \mathrm{Cu}^{+}$, and $\mathrm{Cu}^{2+}$ ions, as oxidation catalysts, in vitamin D3 aqueous solution were evaluated (Table 1). Metal ions-mediated vitamin D3 degradation occurred very quickly, regardless of the particular metal ion and its concentration. Nevertheless, $\mathrm{Fe}^{2+}$ ions were found most efficient, since even the lowest tested concentration of $\mathrm{Fe}^{2+}$ ions $(0.01 \mathrm{mM})$ caused complete vitamin D3 degradation in less than two hours. The catalytic activity of $\mathrm{Cu}^{+}$and $\mathrm{Cu}^{2+}$ ions on the degradation of vitamin D3 was comparable at all three tested concentrations, leading to complete degradation in approximately six hours. However, $\mathrm{Cu}^{+}$-mediated degradation of vitamin D3 showed greater variability than $\mathrm{Cu}^{2+}$-mediated degradation.

To investigate vitamin D3 degradation in more detail, the effects of a mixture of $\mathrm{Cu}^{2+}$ ions and different concentrations of ascorbic acid were evaluated. Vitamin D3 solution without the addition of $\mathrm{Cu}^{2+}$ ions and ascorbic acid was the control sample. Similarly as previously noted, $\mathrm{Cu}^{2+}(2 \mathrm{mM})$ caused very fast vitamin D3 degradation (significantly higher first-order rate constants compared to the control sample, Table 6). The expected the prooxidative effect of the combination of ascorbic acid and $\mathrm{Cu}^{2+}$ ions was not observed. Contrary, the antioxidant activity of ascorbic acid was observed in all solutions, except in the solution with the lowest ascorbic acid concentration (insignificant difference from the solution with the same $\mathrm{Cu}^{2+}$ concentration, without ascorbic acid). Ascorbic acid at a concentration $\geq 500 \mathrm{mg} / \mathrm{L}$ eliminated the degradation effect of the copper ions. The highest tested ascorbic acid concentrations (1000 and $2000 \mathrm{mg} / \mathrm{L}$ ) additionally stabilized the vitamin D3 aqueous solution, as the degradation rate of these two solutions was significantly lower than in the control sample (Table 6).

Table 6. First-order rate constants for vitamin D3 degradation in the presence of $\mathrm{Cu}^{2+}$ ions (alonepoint 0$)$ and in combination with different concentrations of ascorbic acid (A) at $25^{\circ} \mathrm{C}(n=3)$.

\begin{tabular}{cccc}
\hline & A Conc. $(\mathbf{m g} / \mathbf{L})$ & $\mathbf{k}_{\mathbf{1}}\left(\mathbf{h}^{-\mathbf{1}}\right)$ & CI \\
\hline & Control & 0.131 & $0.122-0.141$ \\
& 0 & 0.526 & $0.505-0.548$ \\
$\mathrm{~A}+2 \mathrm{mM} \mathrm{Cu}^{2+}$ & 100 & 0.518 & $0.495-0.542$ \\
& 200 & 0.267 & $0.246-0.291$ \\
& 500 & 0.122 & $0.101-0.147$ \\
& 1000 & 0.036 & $0.033-0.038$ \\
\hline
\end{tabular}

CI-95\% confidence interval; ${ }^{*}$ vitamin D3 in the same media without the addition of ascorbic acid and $\mathrm{Cu}^{2+}$ ions.

\subsection{Approaches towards Vitamin D3 Stabilization in Aqueous Solutions}

Approaches towards stabilizing vitamin D3 in an aqueous solution by the addition of EDTA, citric acid, and ascorbic acid were undertaken. Their stabilizing capability, individually and in various combinations was determined and quantitatively evaluated. The results were statistically analysed by ANOVA and a Tukey post hoc test.

\subsubsection{Addition of an Individual Antioxidant}

The results of the effect of various concentrations of each antioxidant (EDTA, ascorbic or citric acid) on vitamin D3 stability are presented in Figure 5. The antioxidant activity of ascorbic acid was observed at all tested concentration levels. First-order rate constants in 
the presence of ascorbic acid were significantly lower $(p<0.001)$ than in the control sample (without the addition of ascorbic acid). The stabilization effect of ascorbic acid significantly increased with its concentration $(p<0.001)$. At the maximum-tested concentration $(2.0 \mathrm{~g} / \mathrm{L})$, where the reaction rate was about 10 -fold lower than in the control sample, ascorbic acid was unlikely to have achieved the maximum effect.

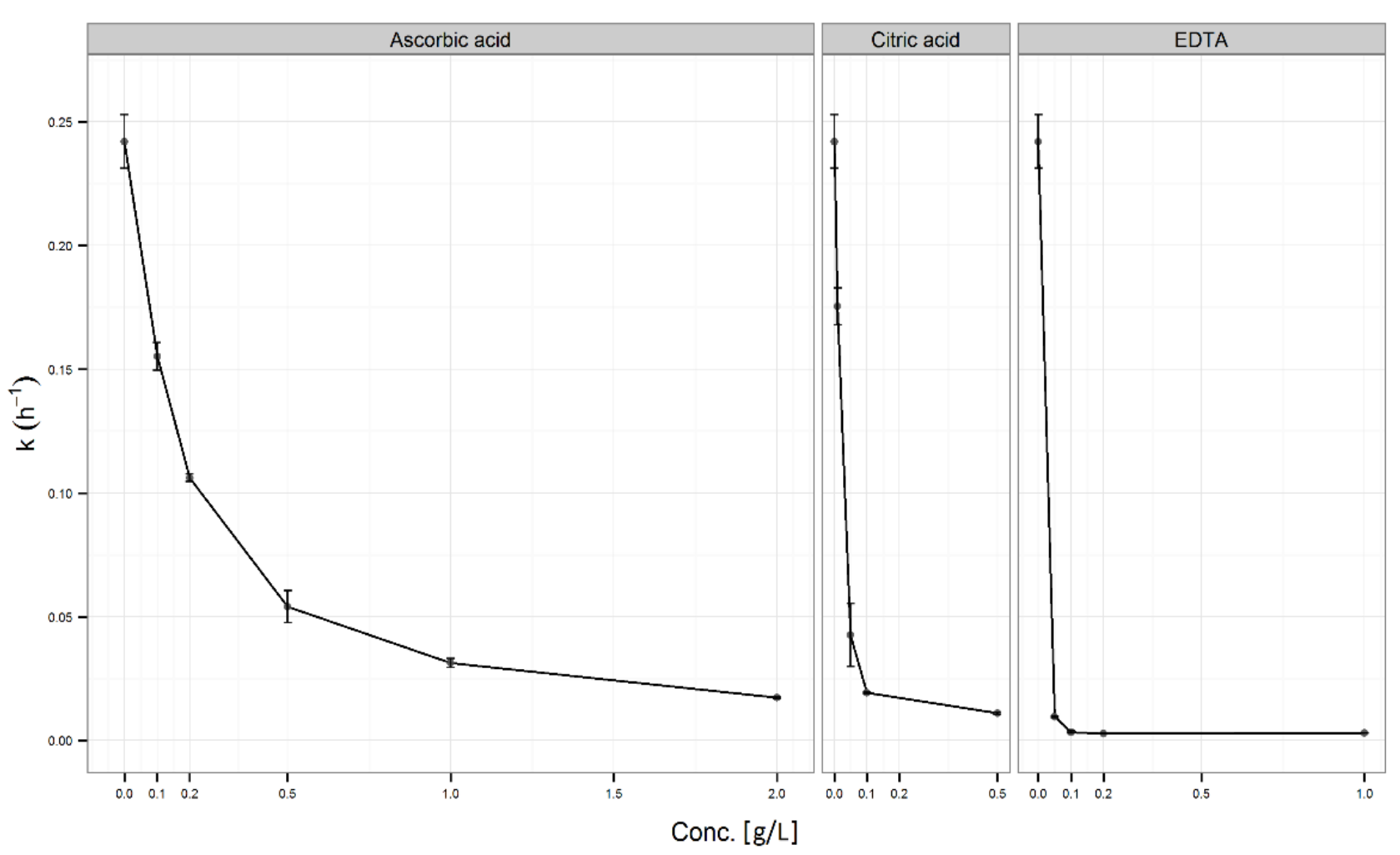

Figure 5. First-order rate constants for vitamin D3 degradation as a function of different concentrations of ascorbic, citric acid, or EDTA at $25^{\circ} \mathrm{C}(n=3)$.

The statistically significant stabilisation of citric acid was observed at all tested concentration levels compared to the control sample (Figure 5). The curve of rate constants as a function of antioxidant concentration for citric acid was similar to that of ascorbic acid, though the maximum citric acid concentration $(0.5 \mathrm{~g} / \mathrm{L})$ stabilized vitamin D3 significantly better than the maximum ascorbic acid concentration $(p<0.001)$.

EDTA was found to be the most effective among the selected antioxidants in the stabilization of vitamin D3 solutions (Figure 5), which was statistically confirmed. The lowest tested EDTA concentration $(0.05 \mathrm{~g} / \mathrm{L})$ stabilized vitamin D3 better than the highest tested ascorbic acid concentration $(p<0.001)$. EDTA reached a maximum stabilizing effect at a concentration of $0.1 \mathrm{~g} / \mathrm{L}$ (no significant differences between the tested EDTA concentrations above $0.1 \mathrm{~g} / \mathrm{L}, p>0.05)$. Statistical evaluation of individual antioxidants (EDTA, ascorbic, and citric acid) at the same concentration $(0.5 \mathrm{~g} / \mathrm{L})$ showed that EDTA stabilized vitamin D3 statistically significantly better than ascorbic or citric acid (Figure 6-Insert). It is also evident that $0.5 \mathrm{~g} / \mathrm{L}$ of citric acid statistically significantly decreased vitamin D3 degradation compared to DW or solution containing $0.5 \mathrm{~g} / \mathrm{L}$ of ascorbic acid. 


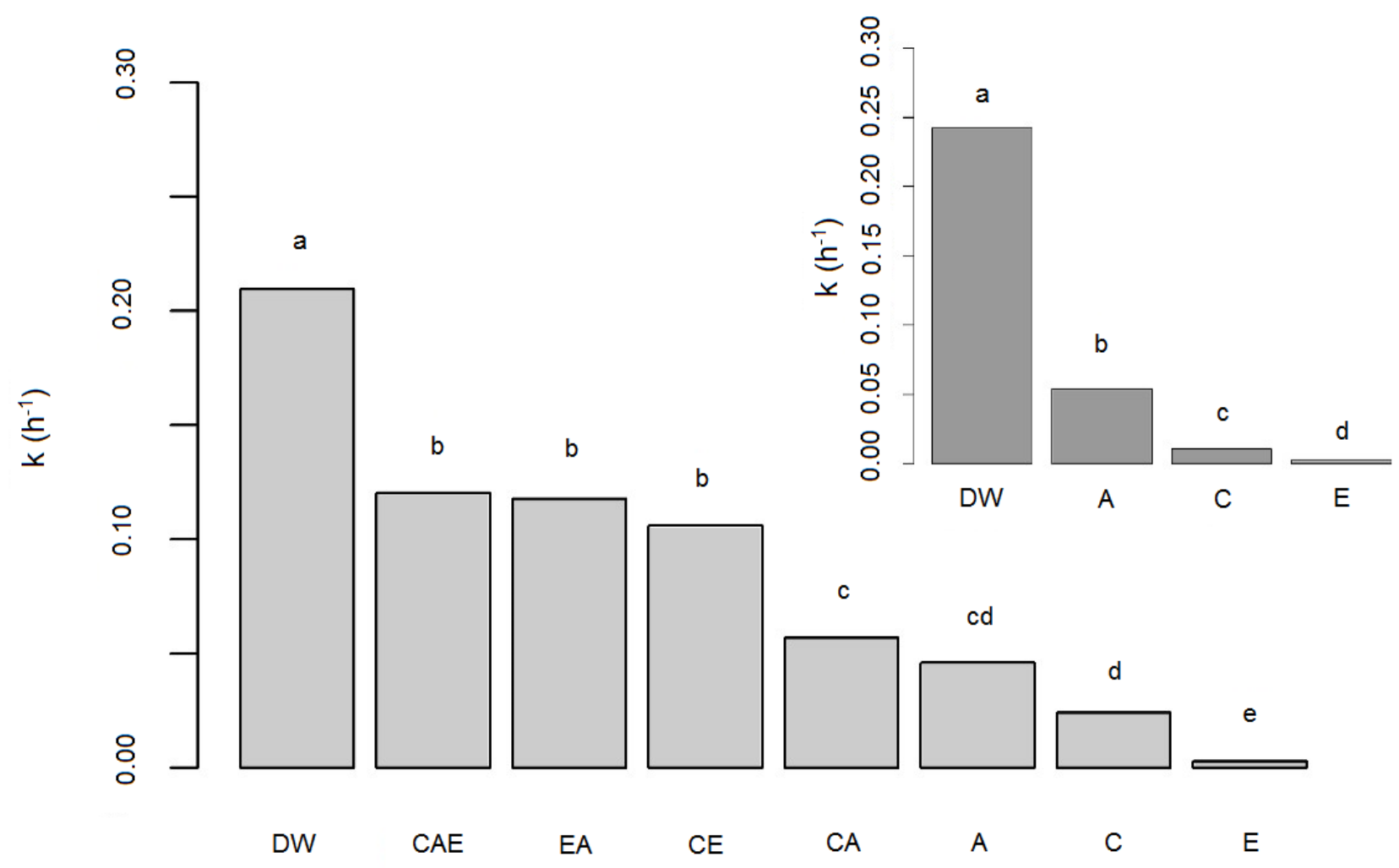

Figure 6. Vitamin D3 stabilization, presented by its first-order rate constants at $25^{\circ} \mathrm{C}$ in distilled water (DW) and after the addition of an individual antioxidant EDTA (E), citric acid (C), ascorbic acid (A), and combinations of two and all three antioxidants (CA, CE, EA, and CAE) $(n=3)$. The columns designated by different letters showed statistical differences from the other groups $(p<0.001)$. Insert-The effect of the same concentration $(0.5 \mathrm{~g} / \mathrm{L})$ of citric acid $(\mathrm{C})$, ascorbic acid (A), or EDTA (E) on vitamin D3 degradation rate at $25^{\circ} \mathrm{C}(n=3)$. The columns designated by different group letters showed statistical differences from other groups $(p<0.001)$.

\subsubsection{Addition of Antioxidant Combinations}

Samples with combinations of these three antioxidants-EDTA, ascorbic, and citric acid-in various concentrations were prepared and evaluated to find a potential synergism among antioxidants. The statistical evaluation of the antioxidant's effectiveness for vitamin D3 stabilization included combinations of two and three antioxidants, as well as individual antioxidants as described in Table 1 and Appendix A Table A1. Statistical method ANOVA revealed differences between the groups $(p<0.001)$. The Tukey post hoc test with respect to the heterogeneity of variances between groups showed statistical differences among groups as designated by different letters in Figure 6 . The addition of antioxidants (individually or in combination) significantly stabilized vitamin D3 compared to its stability in DW (column a). However, EDTA added individually stabilized vitamin D3 aqueous solution more significantly than in any tested combination (column e). Among the tested antioxidant combinations, the combination of citric and ascorbic acid (CA) with a known synergistic effect [46] (column c) was found most effective, while the combination of all three antioxidants (column b) was least effective. In view of these unexpected results, the same experiment was repeated and comparable results were obtained.

\subsection{Vitamin D3 Stability in Liquid Commercial Products}

A study on three medicines and six FSs, all in the form of oral drops and containing vitamin D3 as the main active ingredient, was also performed to evaluate its stability in various formulations. Vitamin D3 stability in these products was evaluated at three isothermal conditions: 4,25 , and $40^{\circ} \mathrm{C}$. The declines in vitamin D3 content were evaluated by first-order kinetics, which fitted its degradation well. Its content remained unchanged 
after 6 months of storage at ambient temperature in approximately half of the tested products and gradually decreased in the other half by up to almost $100 \%$ (Table 7 ).

Table 7. Remaining vitamin D3 with respect to initial content in the tested liquid commercial products after 6 months of storage at 4,25 , and $40{ }^{\circ} \mathrm{C}$ (average \pm relative standard error, $n=3$ ).

\begin{tabular}{|c|c|c|c|c|c|c|c|}
\hline \multicolumn{4}{|c|}{$\begin{array}{c}\text { Vitamin D3 Content (\%) after } 6 \text { Months } \\
\text { in Oil-Based Formulations }\end{array}$} & \multicolumn{4}{|c|}{$\begin{array}{l}\text { Vitamin D3 Content (\%) after } 6 \text { months } \\
\text { in Water-Based Formulations }\end{array}$} \\
\hline & $4^{\circ} \mathrm{C}$ & $25^{\circ} \mathrm{C}$ & $40^{\circ} \mathrm{C}$ & & $4^{\circ} \mathrm{C}$ & $25^{\circ} \mathrm{C}$ & $40^{\circ} \mathrm{C}$ \\
\hline M (1) & $102.0 \pm 0.2$ & $101.0 \pm 0.1$ & $98.3 \pm 0.3$ & M (2) & $101.5 \pm 0.0$ & $101.9 \pm 0.9$ & $102.3 \pm 0.0$ \\
\hline FS (4) & $101.2 \pm 0.2$ & $99.7 \pm 0.2$ & $97.5 \pm 0.2$ & M (3) & $96.7 \pm 0.0$ & $96.0 \pm 1.0$ & $80.5 \pm 2.0$ \\
\hline FS (6) & $91.2 \pm 2.4$ & $89.1 \pm 0.1$ & $46.8 \pm 0.4$ & FS (5) & $66.2 \pm 2.8$ & $1.5 \pm 0.9$ & $0.0 \pm 0.0$ \\
\hline \multirow[t]{2}{*}{ FS (8) } & $102.9 \pm 1.0$ & $102.2 \pm 0.6$ & $100.2 \pm 0.5$ & FS (7) & $93.1 \pm 0.5$ & $79.4 \pm 1.0$ & $40.6 \pm 1.2$ \\
\hline & & & & FS (9) & $76.6 \pm 3.5$ & $39.8 \pm 2.6$ & $2.3 \pm 0.2$ \\
\hline \multicolumn{8}{|c|}{$\begin{array}{l}\text { Quantitative Evaluation of Vitamin D3 Stability in the Unstable Products } \\
\text { (First-Order Constants and Arrh. Data) }\end{array}$} \\
\hline & $\begin{array}{c}\mathrm{k}_{1}\left(4^{\circ} \mathrm{C}\right) \\
\left(\mathrm{month}^{-1}\right)(\mathrm{CI})\end{array}$ & \multicolumn{2}{|c|}{$\begin{array}{c}\mathrm{k}_{1}\left(25^{\circ} \mathrm{C}\right) \\
\left(\text { month }^{-1}\right)(\mathrm{CI})\end{array}$} & $\begin{array}{c}\mathrm{k}_{1}\left(40^{\circ} \mathrm{C}\right) \\
\left(\text { month }^{-1}\right)(\mathrm{CI})\end{array}$ & Arrh. eq. & $R^{2}$ & $\mathrm{Ea}(\mathrm{kJ} / \mathrm{mol})$ \\
\hline FS (5) & $\begin{array}{c}0.069 \\
(0.057-0.081)\end{array}$ & \multicolumn{2}{|c|}{$\begin{array}{c}0.610 \\
(0.362-0.859)\end{array}$} & $\begin{array}{c}2.469 \\
(2.141-2.797)\end{array}$ & $y=-8613 x+28.42$ & 1.000 & 71.6 \\
\hline FS (7) & $\begin{array}{c}0.012 \\
(0.010-0.013)\end{array}$ & \multicolumn{2}{|c|}{$0.038(0.035 .042)$} & $\begin{array}{c}0.150 \\
(0.142-0.159)\end{array}$ & $y=-5987 x+17.08$ & 0.971 & 49.8 \\
\hline FS (9) & $\begin{array}{c}0.045 \\
(0.032-0.058)\end{array}$ & \multicolumn{2}{|c|}{$\begin{array}{c}0.154 \\
(0.136-0.173)\end{array}$} & $\begin{array}{c}0.634 \\
(0.605-0.662)\end{array}$ & $y=-6240 x+19.33$ & 0.972 & 51.9 \\
\hline
\end{tabular}

Arrh. eq.—Arrhenius equation; CI—95\% confidence interval; Ea—activation energy; FS—food supplement; M—medicine.

Regarding ambient storage conditions, vitamin D3 was found to be properly stabilized in all tested oil-based formulations with $<10 \%$ degradation after 6 months. However, the observed degradation after 6-months of storage at an elevated temperature implied that the oil type and its quality is also an important factor for vitamin D3 stability. Vitamin D3 was generally less stable in the water-based formulations (Table 7).

The temperature dependence of vitamin D3 stability was also observed within the finished products' stability study. The effect of the storage temperature on vitamin D3 stability is most evident in products 3, 6, 7, and 9 (Table 7). Vitamin D3 degraded most significantly in FS 5, 7, and 9. The higher storage temperature caused a significant increase in vitamin D3 first-order rate constants in all three water-based FSs. Similar to the three different tested aqueous media (TW, DW, and MQ), vitamin D3 degradation in these three finished products also followed the Arrhenius equation (high coefficient of determination $R^{2}$ ). The calculated activation energy for vitamin D3 in Product 5 correlated well with the activation energies in TW, while in Products 7 and 9 it correlated with DW (Tables 4 and 7).

The performed stability study on vitamin D3 in finished products also provided valuable information on their shelf life after opening at which time medicines contain $>90 \%$ and FSs $>80 \%$ of the vitamins claimed on the label [47]. After being open for at least 6 months, shelf life was confirmed for products 1, 2, 3, 4, 6, and 8 based on the results of the long-term stability study (Table 7). The calculated shelf life after opening for products 5, 7, and 9 were approximately 11 days, 5 months, and 44 days, respectively, but these could be significantly extended to $>3$ months for Product 5, $>22$ months for Product 7 , and $\approx 5$ months for Product 9 if they were stored at a lower temperature (refrigerator).

\section{Discussion}

The main aim of this study was to establish the stability of vitamin D3 in a comprehensive and quantitative manner, which had not yet been described in the literature. The first step was to determine the vitamin D3 degradation kinetics. The selection of the most appropriate kinetic model was based on two statistical parameters $R^{2}$ and AIC, since linear 
regression may overestimate or underestimate the reaction rate depending on the deviation of the experimental data from linearity [48]. The first-order kinetic model was suitable for vitamin D3 degradation under all tested conditions, except light and oxygen, probably due to more complex reaction mechanisms. In these two cases, the established models in chemical kinetics were found to be inappropriate. Therefore, the Weibull kinetic model was introduced, which included a scale constant in addition to the rate constant, thus adding flexibility and well-described vitamin D3 degradation under all tested conditions. In systems with simpler vitamin D3 degradation (all tested conditions except light and oxygen), it was comparable to the first-order model, which was used primarily for its simplicity. The Weibull model has lately found useful application in fields such as modelling microbial reactions [49-51], survival analysis [52-54], and engineering and materials [55-58], but it has rarely been applied to stability data [59].

The vitamin D3 stability study in aqueous solutions (to evaluate the influence of media, temperature, $\mathrm{pH}$, concentration, light, oxygen, and metal ions on its stability) provided useful information for the formulation of stable vitamin D3 products. It also provided a significant upgrade of the existing knowledge on vitamin D3 stability, which is rather inconclusive and only qualitative. Moreover, this study is beneficial for the end-users to distinguish quality products among the wide variety of vitamin D3 products on the market.

The initial conclusion from the performed stability study is that vitamin D3 is very unstable in aqueous media. The significantly higher vitamin D3 stability observed in organic solvents (Figure 1) is probably due to the absence of hydronium and hydroxyl ions, used in hydrolysis, and catalysts for oxidation reactions, such as metal ions [60]. Among the three different tested waters (MQ, DW, and TW), vitamin D3 was found the most stable in MQ and the least stable in DW. Because of the unexpected results, this experiment was repeated and extended to three different temperatures: 4,25 , and $40{ }^{\circ} \mathrm{C}$ to confirm the trend (Table 4). Although temperature mostly accelerates chemical reactions, its role in oxidation reactions is composed as it may also act in the opposite direction due to the lower oxygen solubility at higher temperatures [61]. Therefore, the impact of temperature on compounds susceptible to oxidation, like vitamin D3, requires experimental evaluation. The obtained results followed the general principle: higher temperature led to a statistically significant increase in reaction rate constants (Table 4) and decreased vitamin D3 stability. High correlations $\left(R^{2}\right)$ between calculated rate constants and temperature showed that vitamin D3 degradation in all three aqueous media followed the Arrhenius equation. Obtained activation energies (Table 4) have not yet been published in the literature. Significantly different activation energies indicate alterations in vitamin D3 degradation mechanism in the particular aqueous media, which may be a consequence of metal ions, acting as catalysts in oxidation reactions. Metal ions, which are less likely to be present in ultrapure MQ, lower the activation energy and lead to faster vitamin D3 degradation (higher rate constant) in DW and TW. The results in Table 4 led to the following conclusion of practical importance: vitamin D3 in aqueous solutions may be stabilized by being stored at a lower temperature because there was a statistically significant decrease of first-order rate constants at a lower temperature. The stabilizing effect of lower storage temperature is stronger in MQ than in TW or DW.

Vitamin D3 stability in aqueous solutions was also evaluated for its concentration and the $\mathrm{pH}$ of the solutions as they are both important factors in chemical reactions in solutions. Since the $\mathrm{pH}$ profile for vitamin D3 has not yet been published, the impact of $\mathrm{pH}$ in the range between 1 and 8 was systematically evaluated at $25{ }^{\circ} \mathrm{C}$. Vitamin D3 was found unstable in acidic media and more stable at $\mathrm{pH}$ values above 5 (Figure 2). These results were in contrast to the usual trend for oxidation: lower stability at higher $\mathrm{pH}$ [37]. We consider that the first report of a $\mathrm{pH}$ profile for vitamin $\mathrm{D} 3$ provided beneficial information about the existing qualitative knowledge on its stability in neutral and weak alkaline [38,39] and instability in acidic media $[39,43]$. By evaluating the concentration effect, we concluded that aqueous solutions with lower vitamin D3 concentrations were less stable (Table 5) as a consequence of the greater impact of particular destabilizing factors. 
Vitamin D3 degradation is mostly mediated through oxidative reactions [34,59-61]. Factors that could induce and influence oxidation (e.g., light, oxygen, and metal ions) were thus evaluated. Light induces oxidative reactions, mostly through the formation of free radicals, and causes isomerization. The obtained results of decreased vitamin D3 stability under the influence of light (Figure 3) are supported by several reports in the literature $[31,36,38-41]$ although contradictory data are also found in the published literature $[43,44]$. Possible reasons for the conflicting data are different experimental conditions (e.g., exposure time, light sources and illumination, media, or concentration) or deficient information on the experimental conditions. In a recently published study on vitamin D3-forced degradation, its isomers were observed as degradation products under the influence of light [42], thus confirming the destabilizing effect of light on vitamin D3. Oxygen was also identified as a factor, which significantly decreased the stability of vitamin D3 (Figure 4). However, the air above the solution was not a determining factor for vitamin D3 destabilization.

Metal ions are widespread in the environment and may also be present in finished products. Their source may be the manufacturing equipment, containers, and the used water, or they may be present as impurities in the active ingredients or excipients if used as catalysts in the synthesis processes [62]. Trace metals can act as catalysts in oxidation processes and cause active ingredient degradation [63]. Vitamin D3 incompatibility with trace metals has been indicated in the literature but not experimentally supported [64]. In view of the importance of this subject and the lack of published data, experiments with $\mathrm{Fe}^{2+}, \mathrm{Cu}^{+}$, and $\mathrm{Cu}^{2+}$ ions were performed, which led to the conclusion that vitamin D3 degradation may be catalysed by different metal ions $\left(\mathrm{Fe}^{2+}, \mathrm{Cu}^{+}\right.$, and $\left.\mathrm{Cu}^{2+}\right)$. The potential prooxidative effect of the combination of ascorbic acid and $\mathrm{Cu}^{2+}$ ions, mediated through oxidation-reductive reactions and the formation of reactive species (hydrogen peroxide, hydroxyl, and ascorbic radicals) $[65,66]$, was further evaluated. In this experiment, we only observed the antioxidant activity of ascorbic acid. These results indicate that ascorbic acid and other similar antioxidants could be used as stabilizers of aqueous vitamin D3 solutions, which was further investigated.

The performed stability study in aqueous solutions indicated that vitamin D3 could be stabilized by limiting the effects of destabilizing factors (e.g., storage at a lower temperature and/or at $\mathrm{pH}>5$ ) and active intervention by the addition of stabilizers, which was quantitatively evaluated. The addition of three well-known antioxidants: EDTA, citric acid, and ascorbic acid significantly stabilized vitamin D3 (Figure 5). The antioxidant activity of ascorbic acid is mediated through the reduction of reactive oxygen or nitrogen species or acts as a weak chelating agent $[67,68]$. Citric acid and EDTA effectively remove metal ions by chelation $[67,68]$. Evaluating their stabilization capability at the same concentration, significant differences in the stabilizing effect of EDTA, citric, and ascorbic acid were observed. The stabilizing effect decreased in the stated antioxidants order (Figure 6). Their stabilizing effect was concentration-dependent, except for EDTA at concentrations $\geq 0.1 \mathrm{~g} / \mathrm{L}$ (Figure 5). The wide concentration range of ascorbic acid was selected in view of its potential prooxidative effect, which was not observed (Table 6). Based on the results, we concluded that the use of antioxidants such as EDTA, ascorbic acid, and citric acid, one of the basic techniques for preventing oxidation [68,69], is also beneficial for vitamin D3 stabilization.

Considering the results for vitamin D3 stabilization with individual antioxidants, we anticipated that a combination of two or three would further increase stability. The statistical evaluation, which included all obtained results on vitamin D3 stabilization by the addition of individual antioxidants and their combinations revealed the superior stabilizing effect of EDTA. The observed lower stabilization capability of the combinations may have arisen from the multifunctional effects of the individual stabilizers acting as antioxidants, prooxidants, chelating agents, reducing agents, and oxygen removers. Antioxidant interactions can result in alteration of the microenvironment of one antioxidant by another and competitive oxidation and regeneration between antioxidants [70]. The overall effect 
of their combination on the oxidation of other compounds is not entirely predictable, as also the catalysing power of iron ions is greater when they are in the complex of EDTA. Thus conducted and evaluated experiments are beneficial in view of the wide range of antioxidant concentrations, detection of the potential interactions, and illustration of real situations. Based on these results, we concluded that chelation and elimination of trace metals are crucial for vitamin D3 stabilization.

Basic studies and knowledge of vitamin D3 stability are necessary to ensuring its stability within finished products. Therefore, understanding its instability and acquiring expertise on stabilization approaches are required for providing quality, safe and efficient products with an appropriate shelf life. The knowledge, gained within the vitamin D3 stability study in aqueous solutions was further transferred to commercially available finished products. The results from the vitamin D3 stability study in three medicines and six FSs, all in the form of oral drops (Table 7), are in accordance with results from the stability study of vitamin D3 in solutions (Section 3.2 Vitamin D3 stability study in aqueous solutions and Section 3.3 Approaches towards vitamin D3 stabilization in aqueous solutions). Analogously as observed within the stability study in solution (Section 3.2.1 Effect of the media), we identified the carrier of the formulation as the main contributing factor for vitamin D3 stabilization. Contrary to the tested oil-based formulations, vitamin D3 was found to be unstable in water-based formulations, which are commonly found on the market. Among the tested water-based formulation, we observed a difference between vitamin D3 stabilization within the two tested product categories: medicines and FSs. Although unstable in aqueous solutions, vitamin D3 may be properly stabilized, which was achieved with the formulation of Products 2 and 3, both registered as medicines. The observed vitamin D3 instability in all three water-based FSs (5, 9, and 7) also confirmed our thesis that aqueous vitamin D3 solutions require proper stabilization, which had been neglected or deemed to be of lesser importance for their manufacturers. Namely, Product 7 did not contain any stabilizer or organic solvents. Vitamin D3 was the least stable in FS Product 5, leading to its total degradation after 6 months of storage at the recommended conditions (ambient temperature). Such pronounced vitamin D3 instability was in accordance with our findings, considering the acidic environment of this product $(\mathrm{pH}<3)$, which was identified as one of the key destabilizing factors within the vitamin D3 stability study in aqueous solutions (Section 3.2.3 pH effect). In comparison, the other tested water-based formulations were in the more favourable $\mathrm{pH}$ range according to its $\mathrm{pH}$ profile (between 5.6 and 7.2). Also, the composition of Product 5 did not provide stabilization because it is an aqueous vitamin D3 solution containing only one potential vitamin D3 stabilizer-citric acid. However, its presence at high concentrations had a destabilizing effect on vitamin D3 because it created an acidic environment.

The findings, presented in Section 3.3 Approaches towards vitamin D3 stabilization in aqueous solutions indicated the importance of the products' excipients as they may contribute towards vitamin D3 stabilization. Product 2 (Table 7) is an example of the proper stabilization of aqueous vitamin D3 solutions, which was achieved by adding butylated hydroxytoluene and citric acid as antioxidants. Product 3 was the least stable tested medicine. However, with $4 \%$ degradation after 6 months of storage at room temperature, it was an acceptable formulation for vitamin D3 stability. Vitamin D3 stabilization in this product was most probably achieved by the addition of organic solvents (propylene glycol and ethanol), in which vitamin D3 was found to be quite stable (Section 3.2.1 Effect of the media). Different vitamin D3 stabilization in the tested products was also reflected in the different shelf life provided by the manufacturers (between 1 and 5 years). Only one of the tested products, Product 1, specified a shelf life after opening of 6 months, which was confirmed in this study.

The determined temperature dependence of vitamin D3 stability in aqueous solutions (Table 4) was also confirmed by the comparable activation energies in the less stable products (Table 7). An interesting and practical conclusion, based on temperature dependence, is the possibility of a significant extension of shelf life after opening by storing the prod- 
ucts at a lower temperature. On the other hand, considering the high stability of vitamin $\mathrm{D}$ in Product 2 (Table 7), refrigerator storage, as recommended by the manufacturers, seems unnecessary. These results also provide a foundation to redefine the recommended storage conditions.

Vitamin D3 stability in aqueous solutions was found to be concentration-dependent (Table 5). Considering these results, vitamin D3 concentration presumably also contributes to its stability in finished products. However, despite having high stability in the medicine and FS with the highest vitamin D3 concentration tested products, a straightforward relation could not be postulated because of the different compositions of the tested products. Considering the different levels of stability in products with a comparable vitamin D3 concentration (Products 2 and 7 and Products 3 and 8, Table 7) and the high concentration in the least stable product (FS (5) in Table 7), it can be concluded that vitamin D3 stability in finished products is primarily dependent on the formulation (medium and excipients). Vitamin D3 stability in solutions was also found dependent on its exposure to light (Section 3.2.5 Effect of light exposure). All manufacturers recognized the risk of vitamin D3 degradation under the influence of light and thus selected containers, which provide light protection (amber glass or plastic bottles).

The results on vitamin D3 stability in finished products were also compared to the results of a previous preliminary stability study [28], performed on different LOTs of the same three medicines (Products 1, 2, and 3 in Table 2). The stability of vitamin D3 in Products 1 and 2 was comparable. Although vitamin D3 was the least stable among the tested medicines in Product 3 (Table 7), its stability had been considerable improved within this product during the 2.5 years between both stability studies. Namely, the revealed $\approx 15 \%$ decline after 6 months at $25{ }^{\circ} \mathrm{C}$ and almost $50 \%$ decline at $40{ }^{\circ} \mathrm{C}$ within the preliminary study [28] was reduced to $\approx 4 \%$ at $25{ }^{\circ} \mathrm{C}$ and $\approx 20 \%$ decline at $40{ }^{\circ} \mathrm{C}$ (Table 7 ). Aware of the suboptimal vitamin D3 stability within the formulation, the manufacturer presumably aimed toward improving stabilization. Because the same qualitative compositions were on the labels of both tested LOTs, we assumed that the manufacturer changed the proportions between the excipients to achieve better vitamin D3 stability.

The tested antioxidants in Section 3.3 Approaches towards vitamin D3 stabilization in aqueous solutions (ascorbic acid, citric acid, and EDTA) are physiologically acceptable and suitable for stabilizing vitamin D3. Since EDTA was found to be the most efficient antioxidant in aqueous vitamin D3 solutions (Figure 6), adding it to increase vitamin D3 stability in finished products would be a valuable proposal.

\section{Conclusions}

Vitamin D3 degradation pathways and kinetics are rather complex and unclear. The effects of various factors (media, temperature, $\mathrm{pH}$, concentration, light, oxygen, metal ions) on its stability in aqueous solutions were clarified in this study, which could help resolve the confusion and contradictions in the literature regarding its stability. The comprehensive and quantitative stability evaluation initially required the selection of the most appropriate model to describe the degradation kinetics. The established kinetic models (zero-, first- and second-order kinetics) did not fit well the degradation of vitamin D3 under all conditions, thus necessitating a more flexible and advanced approach. The Weibull model, which is an upgrade of the commonly used models, was found appropriate for degradation under all tested conditions, including the more complex degradation under the influence of light and oxygen. In cases other than these two, vitamin D3 degradation also followed first-order kinetics, which was applied because of its simplicity. Vitamin D3 was found to be very unstable in aqueous solutions and particularly sensitive to the presence of metal ions and low $\mathrm{pH}$ values. Nevertheless, liquid vitamin D3 products are commonly aqueous solutions, which requires appropriate stabilization. The results obtained from the vitamin D3 stability study in liquid products disclosed significantly lower vitamin D3 stability in water-based compared to oil-based formulations. We also concluded that manufacturers of food supplements pay less attention to stability even though it is essential for assuring 
quality, safety, and efficacy. The results obtained from the vitamin D3 stability study in aqueous solutions and commercial liquid products highlight the importance of a suitable formulation, mainly by the selection of proper $\mathrm{pH}$ value, elimination of metal ions, and addition of certain stabilizers. These results are undoubtedly a useful foundation for the formulation of stable vitamin D3 products given their frequent worldwide use.

Author Contributions: Conceptualization, R.R.; data curation, Ž.T.R.; formal analysis, Ž.T.R. and M.P.; funding acquisition, R.R. and A.K.; investigation, Ž.T.R. and M.P.; methodology, R.R., Ž.T.R. and M.P.; project administration, R.R. and A.K.; resources, R.R. and A.K.; supervision, R.R.; validation: R.R.; visualization, Ž.T.R. and M.P.; writing—original draft preparation, Ž.T.R.; writing—review and editing, Ž.T.R., R.R., M.P. and A.K. All authors have read and agreed to the published version of the manuscript.

Funding: This research was funded by Slovenian Research Agency (ARRS), grant number [P1-0189]. Institutional Review Board Statement: Not applicable.

Informed Consent Statement: Not applicable.

Data Availability Statement: Data is contained within the article.

Conflicts of Interest: The authors declare no conflict of interest.

\section{Appendix A}

Table A1. Information on the tested antioxidant combinations for vitamin D3 stabilization (vitamin D3 concentration was $20 \mathrm{mg} / \mathrm{L}$ in all cases).

\begin{tabular}{cccc}
\hline Mark & C $(\mathbf{m g} / \mathrm{L})$ & EDTA $(\mathbf{m g} / \mathbf{L})$ & A $(\mathbf{m g} / \mathbf{L})$ \\
\hline CE 1 & 5.00 & 50.0 & - \\
CA 1 & 5.00 & - & 100 \\
EA 1 & - & 50.0 & 100 \\
CEA 1 & 5.00 & 50.0 & 100 \\
CE 2 & 50.0 & 500 & - \\
CA 2 & 50.0 & - & 500 \\
EA 2 & - & 500 & 500 \\
CEA 2 & 50.0 & 500 & 500 \\
CE 3 & 500 & 200 & - \\
CA 3 & 500 & - & 2000 \\
EA 3 & - & 200 & 2000 \\
CEA 3 & 500 & 200 & 2000 \\
CE 4 & 500 & 1000 & - \\
CA 4 & 500 & - & 5000 \\
EA 4 & - & 1000 & 5000 \\
CEA 4 & 500 & 1000 & 5000
\end{tabular}

CE-a combination of citric acid and EDTA; CA—a combination of citric and ascorbic acid; EA—a combination of EDTA and ascorbic acid; CEA—a combination of citric acid, EDTA, and ascorbic acid.

\section{References}

1. Goltzman, D. Functions of Vitamin D in Bone. Histochem. Cell Biol. 2018, 149, 305-312. [CrossRef]

2. Holick, M.F. High Prevalence of Vitamin D Inadequacy and Implications for Health. Mayo Clin. Proc. 2006, 81, 353-373. [CrossRef]

3. Holick, M.F.; Chen, T.C. Vitamin D Deficiency: A Worldwide Problem with Health Consequences. Am. J. Clin. Nutr. 2008, 87, 1080S-1086S. [CrossRef]

4. Abdo, J.; Rai, V.; Agrawal, D.K. Interplay of Immunity and Vitamin D: Interactions and Implications with Current IBD Therapy. Curr. Med. Chem. 2017, 24, 852-867. [CrossRef]

5. Bartosik-Psujek, H.; Psujek, M. Vitamin D as an Immune Modulator in Multiple Sclerosis. Neurol. Neurochir. Pol. 2019, 53, 113-122. [CrossRef] [PubMed]

6. Berridge, M.J. Vitamin D Deficiency and Diabetes. Biochem. J. 2017, 474, 1321-1332. [CrossRef] [PubMed]

7. Bivona, G.; Gambino, C.M.; Iacolino, G.; Ciaccio, M. Vitamin D and the Nervous System. Neurol. Res. 2019, 41, 827-835. [CrossRef] [PubMed] 
8. Cyprian, F.; Lefkou, E.; Varoudi, K.; Girardi, G. Immunomodulatory Effects of Vitamin D in Pregnancy and Beyond. Front. Immunol. 2019, 10, 2739. [CrossRef] [PubMed]

9. Ma, Y.; Johnson, C.S.; Trump, D.L. Mechanistic Insights of Vitamin D Anticancer Effects. Vitam. Horm. 2016, 100, 395-431.

10. Norman, P.E.; Powell, J.T. Vitamin D and Cardiovascular Disease. Circ. Res. 2014, 114, 379-393. [CrossRef]

11. Osanai, M.; Lee, G.-H. CYP24A1-Induced Vitamin D Insufficiency Promotes Breast Cancer Growth. Oncol. Rep. 2016, 36, 2755-2762. [CrossRef] [PubMed]

12. Sergeev, I.N. Vitamin D-Mediated Apoptosis in Cancer and Obesity. Horm. Mol. Biol. Clin. Investig. 2014, 20 , 43-49. [CrossRef] [PubMed]

13. Sergeev, I.N. Vitamin D Status and Vitamin D-Dependent Apoptosis in Obesity. Nutrients 2020, 12, 1392. [CrossRef]

14. Wimalawansa, S.J. Associations of Vitamin D with Insulin Resistance, Obesity, Type 2 Diabetes, and Metabolic Syndrome. J. Steroid Biochem. Mol. Biol. 2018, 175, 177-189. [CrossRef] [PubMed]

15. Alexander, J.; Tinkov, A.; Strand, T.A.; Alehagen, U.; Skalny, A.; Aaseth, J. Early Nutritional Interventions with Zinc, Selenium and Vitamin D for Raising Anti-Viral Resistance against Progressive COVID-19. Nutrients 2020, 12, 2358. [CrossRef]

16. Ali, N. Role of Vitamin D in Preventing of COVID-19 Infection, Progression and Severity. J. Infect. Public Health 2020, 13, 1373-1380. [CrossRef]

17. Bilezikian, J.P.; Bikle, D.; Hewison, M.; Lazaretti-Castro, M.; Formenti, A.M.; Gupta, A.; Madhavan, M.V.; Nair, N.; Babalyan, V.; Hutchings, N.; et al. Mechanisms in endocrinology: Vitamin D and COVID-19. Eur. J. Endocrinol. 2020, 183, R133-R147. [CrossRef]

18. Grant, W.B.; Lahore, H.; McDonnell, S.L.; Baggerly, C.A.; French, C.B.; Aliano, J.L.; Bhattoa, H.P. Evidence That Vitamin D Supplementation Could Reduce Risk of Influenza and COVID-19 Infections and Deaths. Nutrients 2020, 12, 988. [CrossRef]

19. Mercola, J.; Grant, W.B.; Wagner, C.L. Evidence Regarding Vitamin D and Risk of COVID-19 and Its Severity. Nutrients 2020, 12, 3361. [CrossRef]

20. Mohan, M.; Cherian, J.J.; Sharma, A. Exploring Links between Vitamin D Deficiency and COVID-19. PLoS Pathog. 2020, 16, e1008874. [CrossRef]

21. Panfili, F.M.; Roversi, M.; D’Argenio, P.; Rossi, P.; Cappa, M.; Fintini, D. Possible Role of Vitamin D in Covid-19 Infection in Pediatric Population. J. Endocrinol. Investig. 2021, 44, 27-35. [CrossRef] [PubMed]

22. Radujkovic, A.; Hippchen, T.; Tiwari-Heckler, S.; Dreher, S.; Boxberger, M.; Merle, U. Vitamin D Deficiency and Outcome of COVID-19 Patients. Nutrients 2020, 12, 2757. [CrossRef] [PubMed]

23. Weir, E.K.; Thenappan, T.; Bhargava, M.; Chen, Y. Does Vitamin D Deficiency Increase the Severity of COVID-19? Clin. Med. Lond. 2020, 20, e107-e108. [CrossRef] [PubMed]

24. Xu, Y.; Baylink, D.J.; Chen, C.-S.; Reeves, M.E.; Xiao, J.; Lacy, C.; Lau, E.; Cao, H. The Importance of Vitamin d Metabolism as a Potential Prophylactic, Immunoregulatory and Neuroprotective Treatment for COVID-19. J. Transl. Med. 2020, 18, 322. [CrossRef]

25. Holick, M.F. The Vitamin D Deficiency Pandemic: Approaches for Diagnosis, Treatment and Prevention. Rev. Endocr. Metab. Disord. 2017, 18, 153-165. [CrossRef]

26. Palacios, C.; Gonzalez, L. Is Vitamin D Deficiency a Major Global Public Health Problem? J. Steroid Biochem. Mol. Biol. 2014, 144 Pt A, 138-145. [CrossRef]

27. Temova Rakuša, Ž.; Roškar, R. Vitamin D in Supplements and Medicines. In Vitamin D Deficiency: Causes and Treatment; Sofi, N.Y., Mandal, A., Amiri, W., Eds.; Open Access eBooks: Las Vegas, NV, USA, 2018; pp. 1-19.

28. Temova, Ž.; Roškar, R. Shelf Life after Opening of Prescription Medicines and Supplements with Vitamin D3 for Paediatric Use. Eur. J. Hosp. Pharm. 2017, 24, 115-119. [CrossRef]

29. Stability Testing of New Drug Substances and Products ICH Q1A(R2). 2003. Available online: https://www.ich.org/ products/guidelines/quality/qualitysingle/article/stability-testing-of-new-drug-substances-and-products.html (accessed on 13 May 2018).

30. Zareie, M.; Abbasi, A.; Faghih, S. Thermal Stability and Kinetic Study on Thermal Degradation of Vitamin D3 in Fortified Canola Oil. J. Food Sci. 2019, 84, 2475-2481. [CrossRef]

31. Grady, L.T.; Thakker, K.D. Stability of Solid Drugs: Degradation of Ergocalciferol (Vitamin D2) and Cholecalciferol (Vitamin D3) at High Humidities and Elevated Temperatures. J. Pharm. Sci. 1980, 69, 1099-1102. [CrossRef]

32. Sharifi, F.; Jahangiri, M. Investigation of the Stability of Vitamin D in Emulsion Based Delivery Systems. Chem. Ind. Chem. Eng. Q. 2017, 24, 28. [CrossRef]

33. Jafari, T.; Askari, G.; Mirlohi, M.; Javanmard, S.H.; Faghihimani, E.; Fallah, A.A. Stability of Vitamin D3 in Fortified Yoghurt and Yoghurt Drink (Doogh). Adv. Biomed. Res. 2016, 5, 52.

34. Mahmoodani, F.; Perera, C.O.; Fedrizzi, B.; Abernethy, G.; Chen, H. Degradation Studies of Cholecalciferol (Vitamin D3) Using HPLC-DAD, UHPLC-MS/MS and Chemical Derivatization. Food Chem. 2017, 219, 373-381. [CrossRef]

35. Mahmoodani, F.; Perera, C.O.; Abernethy, G.; Fedrizzi, B.; Chen, H. Lipid Oxidation and Vitamin D3 Degradation in Simulated Whole Milk Powder as Influenced by Processing and Storage. Food Chem. 2018, 261, 149-156. [CrossRef]

36. Combs, G.F. Chemical and Physiological Properties of Vitamins. In The Vitamins: Fundamental Aspects in Nutrition and Health, 3rd ed.; Elsevier Academic Press: Amsterdam, The Netherlands, 2008; pp. 503-514.

37. Eitenmiller, R.R.; Landen, W.O.; Lin, Y. Vitamin Analysis for the Health and Food Sciences, 2nd ed.; CRC Press: Boca Raton, FL, USA, 2008.

38. Kutsky, R.J. Handbook of Vitamins, Minerals and Hormones, 2nd ed.; Van Nostrand Reinhold Company: New York, NY, USA, 1981. 
39. Fanali, C.; D’Orazio, G.; Fanali, S.; Gentili, A. Advanced Analytical Techniques for Fat-Soluble Vitamin Analysis. Trends Anal. Chem. 2017, 87, 82-97. [CrossRef]

40. Praminik, B.N.; Lee, M.S.; Guodong, C. Characterization of Impurities and Degradants Using Mass Spectrometry; John Wiley: New York, NY, USA, 2011.

41. Charlton, S.; Ewing, W. The Vitamins Directory, 2nd ed.; Context Products Ltd.: Leicestershire, UK, 2007.

42. Temova, Ž.; Roškar, R. Stability-Indicating HPLC-UV Method for Vitamin D3 Determination in Solutions, Nutritional Supplements and Pharmaceuticals. J. Chromatogr. Sci. 2016, 54, 1180-1186. [CrossRef]

43. Pike, R.L.; Brown, M.L. Nutrition, an Integrated Approach, 2nd ed.; John Wiley and Sons: Chichester, UK, 1975.

44. Kreutler, P.A.; Czajka-Narins, D.M. Nutrition in Perspective, 2nd ed.; Prentice-Hall: Hoboken, NJ, USA, 1987.

45. R Core Team. The R Project for Statistical Computing; R Foundation for Statistical Computing: Vienna, Austria, 2020; Available online: https: / /www.r-project.org/ (accessed on 19 April 2021).

46. Privett, O.S.; Quackenbush, F.W. The Relation of Synergist to Antioxidant in Fats. J. Am. Oil Chem. Soc. 1954, 31, 321-323. [CrossRef]

47. European Commission Guidance Document for Competent Authorities for the Control of Compliance with EU Legislation. Available online: https:/ / ec.europa.eu/food/sites/food/files/safety/docs/labelling_nutrition-vitamins_minerals-guidance_ tolerances_1212_en.pdf (accessed on 11 November 2017).

48. Corradini, M.G.; Peleg, M. A model of non-isothermal degradation of nutrients, pigments and enzymes. J. Sci. Food Agric. 2004, 84, 217-226. [CrossRef]

49. Peleg, M. Modeling the Dynamic Kinetics of Microbial Disinfection with Dissipating Chemical Agents-A Theoretical Investigation. Appl. Microbiol. Biotechnol. 2021, 105, 539-549. [CrossRef] [PubMed]

50. Chakraborty, S.; Rao, P.S.; Mishra, H.N. Empirical Model Based on Weibull Distribution Describing the Destruction Kinetics of Natural Microbiota in Pineapple (Ananas comosus L.) Puree during High-Pressure Processing. Int. J. Food Microbiol. 2015, 211, 117-127. [CrossRef]

51. Stone, G.; Chapman, B.; Lovell, D. Development of a Log-Quadratic Model to Describe Microbial Inactivation, Illustrated by Thermal Inactivation of Clostridium Botulinum. Appl. Environ. Microbiol. 2009, 75, 6998-7005. [CrossRef]

52. Jones, M.C.; Noufaily, A.; Burke, K. A Bivariate Power Generalized Weibull Distribution: A Flexible Parametric Model for Survival Analysis. Stat. Methods Med. Res. 2020, 29, 2295-2306. [CrossRef]

53. Gómez-Acebo, I.; Dierssen-Sotos, T.; Palazuelos-Calderón, C.; Pérez-Gómez, B.; Amiano, P.; Guevara, M.; Molina, A.J.; Domingo, L.; Fernández-Ortiz, M.; Moreno, V.; et al. Tumour Characteristics and Survivorship in a Cohort of Breast Cancer: The MCC-Spain Study. Breast Cancer Res. Treat. 2020, 181, 667-678. [CrossRef]

54. Jácome, A.A.A.; Wohnrath, D.R.; Scapulatempo Neto, C.; Carneseca, E.C.; Serrano, S.V.; Viana, L.S.; Nunes, J.S.; Martinez, E.Z.; Santos, J.S. Prognostic Value of Epidermal Growth Factor Receptors in Gastric Cancer: A Survival Analysis by Weibull Model Incorporating Long-Term Survivors. Gastric Cancer 2014, 17, 76-86. [CrossRef] [PubMed]

55. Quinn, J.B.; Quinn, G.D. A Practical and Systematic Review of Weibull Statistics for Reporting Strengths of Dental Materials. Dent. Mater. 2010, 26, 135-147. [CrossRef]

56. Zhu, Z.; Zhang, C.; Meng, S.; Shi, Z.; Tao, S.; Zhu, D. A Statistical Damage Constitutive Model Based on the Weibull Distribution for Alkali-Resistant Glass Fiber Reinforced Concrete. Materials 2019, 12, 1908. [CrossRef]

57. Yatongchai, C.; Wren, A.W.; Curran, D.J.; Hornez, J.-C.; Mark, R.T. Comparison of the Weibull Characteristics of Hydroxyapatite and Strontium Doped Hydroxyapatite. J. Mech. Behav. Biomed. Mater. 2013, 21, 95-108. [CrossRef] [PubMed]

58. Genet, M.; Houmard, M.; Eslava, S.; Saiz, E.; Tomsia, A.P. A Two-Scale Weibull Approach to the Failure of Porous Ceramic Structures Made by Robocasting: Possibilities and Limits. J. Eur. Ceram. Soc. 2013, 33, 679-688. [CrossRef] [PubMed]

59. Jiang, L.; Zheng, H.; Lu, H. Weibull Method to model Ascorbic acid Degradation. J. Food Process. Preserv. 2014, 38, 856-863. [CrossRef]

60. Mahmoodani, F.; Perera, C.O.; Abernethy, G.; Fedrizzi, B.; Greenwood, D.; Chen, H. Identification of Vitamin D3 Oxidation Products Using High-Resolution and Tandem Mass Spectrometry. J. Am. Soc. Mass Spectrom. 2018, 29, 1442-1455. [CrossRef] [PubMed]

61. Tromans, D. Temperature and Pressure Dependent Solubility of Oxygen in Water: A Thermodynamic Analysis. Hydrometallurgy 1998, 48, 327-342. [CrossRef]

62. Fliszar, K.A.; Walker, D.; Allain, L. Profiling of Metal Ions Leached from Pharmaceutical Packaging Materials. PDA J. Pharm. Sci. Technol. 2006, 60, 337-342. [PubMed]

63. Ali, M.E.; Rahman, M.M.; Sarkar, S.M.; Hamid, S.B.A. Heterogeneous Metal Catalysts for Oxidation Reactions. J. Nanomater. 2014, 1, 1-23. [CrossRef]

64. Scientific Opinion on the Safety and Efficacy of Vitamin D3 (Cholecalciferol) as a Feed Additive for All Animal Species or Categories Based on a Dossier Submitted by Lohmann Animal Health GmbH. EFSA J. 2014, 12, 3568.

65. Zhou, P.; Zhang, J.; Zhang, Y.; Liu, Y.; Liang, J.; Liu, B.; Zhang, W. Generation of Hydrogen Peroxide and Hydroxyl Radical Resulting from Oxygen-Dependent Oxidation of L-Ascorbic Acid via Copper Redox-Catalyzed Reactions. RSC Adv. 2016, 6, 38541-38547. [CrossRef]

66. Buettner, G.R.; Jurkiewicz, B.A. Catalytic Metals, Ascorbate and Free Radicals: Combinations to Avoid. Radiat Res. 1996, 145, 532-541. [CrossRef] [PubMed] 
67. Stanner, S.; Weichselbaum, E. Antioxidants. In Encyclopedia of Human Nutrition, 3rd ed.; Caballero, B., Ed.; Academic Press: Waltham, MA, USA, 2013; pp. 88-99.

68. Allen, K. Metal chelators as antioxidants for food preservation. In Handbook of Antioxidants for Foos Preservation; Shahidi, F., Ed.; Woodhead Publishing Series in Food Science; Technology and Nutrition: Cambridge, UK, 2015; pp. 79-104.

69. Cantu, A.; Gozza, A.; Waterhouse, A. Chelating Agents: A New Tool in Preventing Wine Oxidation. Am. J. Enol. Vitic. 2009, 60,397a-398a.

70. Choe, E.; Min, D.B. Mechanisms of Antioxidants in the Oxidation of Foods. Compr. Rev. Food Sci. Food Saf. 2009, 8, 345-358. [CrossRef] 